\title{
A global change-induced biome shift in the Montseny mountains (NE Spain)
}

\author{
JOSEP PEÑUELAS* and MARTÍ BOADA $\dagger$ \\ *Unitat Ecofisiologia CSIC-CREAF, CREAF (Center for Ecological Research and Forestry Applications), Edifici C, Universitat \\ Autònoma de Barcelona, 08193 Bellaterra, Catalonia, Spain, †Departament de Geografia, Universitat Autònoma de Barcelona, \\ 08193 Bellaterra, Catalonia, Spain
}

\begin{abstract}
Shifts in plant species and biome distribution in response to warming have been described in past climate changes. However, reported evidence of such shifts under current climate change is still scarce. By comparing current and 1945 vegetation distribution in the Montseny mountains (Catalonia, NE Spain), we report here a progressive replacement of cold-temperate ecosystems by Mediterranean ecosystems. Beech (Fagus sylvatica) forest has shifted altitudinally upwards by ca. $70 \mathrm{~m}$ at the highest altitudes $(1600-1700 \mathrm{~m})$. Both the beech forests and the heather (Calluna vulgaris) heathlands are being replaced by holm oak (Quercus ilex) forest at medium altitudes (800-1400 m). This beech replacement has been observed to occur through a progressive isolation and degradation of beech stands. In 'isolated' (small and surrounded by holm oaks) beech stands, beech trees are $30 \%$ more defoliated, beech recruitment is $41 \%$ lower, and holm oak recruitment is three times higher than in 'continental' (large and continuous) beech stands. The progressively warmer conditions, complemented by the land use changes (mainly the cessation of traditional land management) are the apparent causes, providing a paradigmatic example of global change affecting distributions of plant species and biomes.

Keywords: altitudinal shift, biome replacement, Calluna heathland, climate change, defoliation status, Fagus sylvatica, land use change, Mediterranean forest, Montseny mountains, Quercus ilex, recruitment, temperate forest
\end{abstract}

Received 30 April 2002; revised version received and accepted 18 June 2002

\section{Introduction}

Climatic regimes determine species distributions through species-specific physiological thresholds of temperature and water availability (Woodward, 1987). Shifts in plant species and biome distribution towards the poles or higher altitudes in response to warming have been described in past climate changes (Gates, 1993) and it is considered clear now that poleward and altitudinal upward shifts of species ranges have also occurred across a wide range of taxonomic groups and geographical locations during the 20th century in response to current climate warming (IPCC, 2001a; Walther et al., 2002). However, in fact, actual evidence of plant species

Correspondence: Josep Peñuelas, Unitat Ecofisiologia CSICCREAF, CREAF (Center for Ecological Research and Forestry Applications), Edifici C, Universitat Autònoma de Barcelona, 08193 Bellaterra, Catalonia, Spain, e-mail: josep.penuelas@uab.es altitudinal shifts is still scarce (Wardle \& Coleman, 1992; Grabherr et al., 1994; Kullman, 2001) despite such shifts being easier to discern in plants than in animals, which may exhibit large fluctuations from year to year. Plant shifts follow from the slow processes of population extinctions and colonizations, and therefore it is easier to detect true geographical shifts than in animals since change is more methodical and missing data is less important.

The medium and highest altitudes (800-1700 $\mathrm{m}$ a.s.l) of the Montseny mountains in Catalonia (NE Spain) constitute one of the ecotonic southern distribution areas of Fagus sylvatica (beech) forest and Calluna vulgaris (heather) heathlands in western Europe (Bolòs \& Vigo, 1990). At lower altitudes of Montseny mountains (less than ca. $800 \mathrm{~m}$ a.s.l) the vegetation is typically Mediterranean, with dominance of the Quercus ilex (holm oak) forests. As Montseny beech forests and heather heathlands represent quite an extreme of their distribution area (Fig. 1), they are 

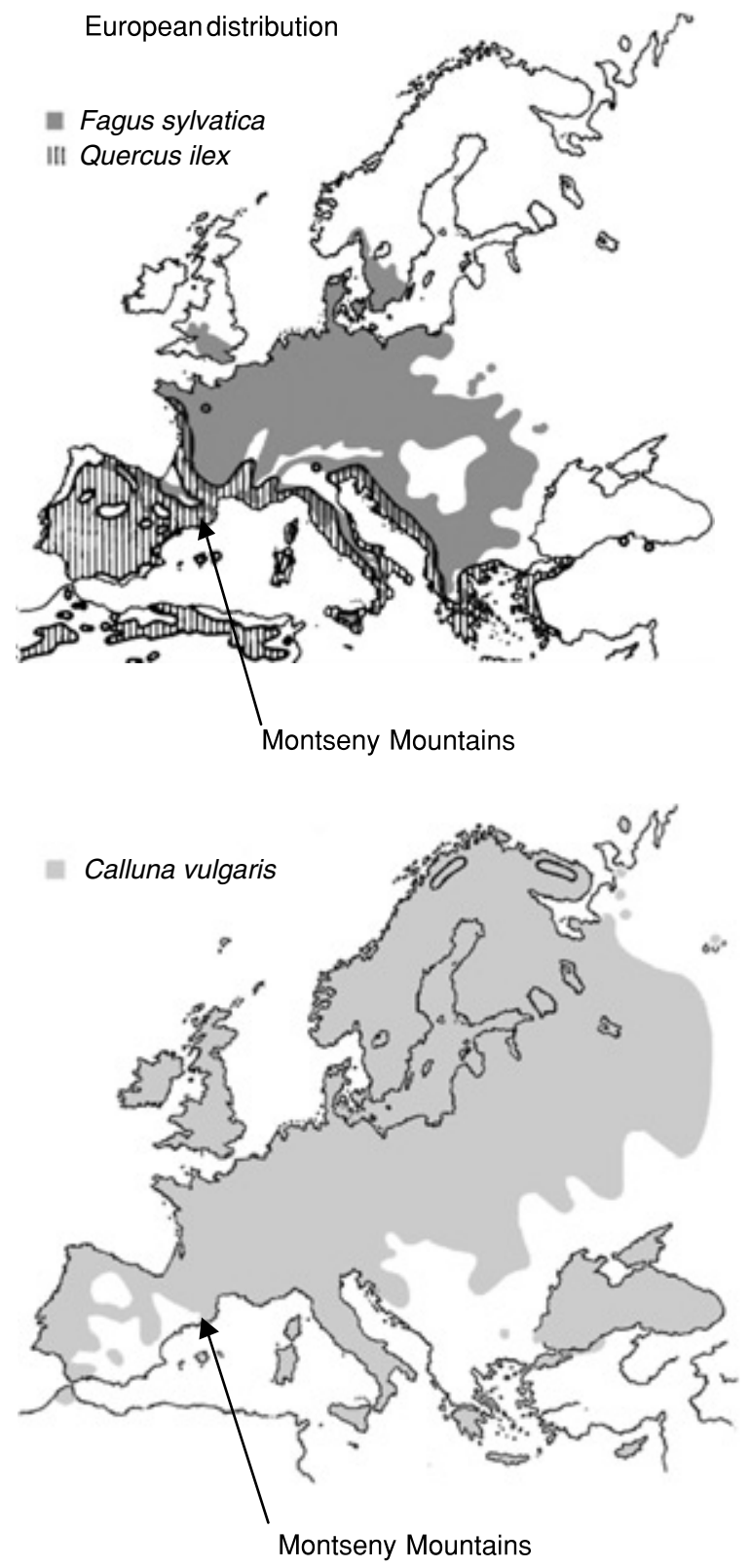

Fig. 1 The distribution of beech (Fagus sylvatica), heather (Calluna vulgaris) (temperate biome), and holm oak (Quercus ilex) (Mediterranean biome) in Europe (Bolòs \& Vigo, 1990).

especially sensitive to environmental changes such as climate and land use change. Average annual temperatures in Montseny have increased by $1.2-1.4^{\circ} \mathrm{C}$ since 1950 while the total amount of annual precipitation remained unchanged (Boada, 2001; Peñuelas et al., 2002) (Fig. 2). As a consequence, the flora and fauna of this region have already shown significant alterations in their life cycles during the last five decades (Peñuelas \& Filella, 2001; Peñuelas et al., 2002) and northward shifts in geographical ranges of its butterfly species have been reported (Parmesan et al., 1999). Montseny mountains have also been submitted to important land use changes during the last decades, including a declaration of Natural Park in 1977. This declaration, together with the decrease in firewood demand due to its substitution by fossil fuels, represented the cessation of traditional management practices such as shepherd fires and coppicing for charcoal.

These climate and land use changes led us to hypothesize (1) an upward altitudinal shift of the temperate beech (Fagus sylvatica) forest and the temperate heather (Calluna vulgaris) heathlands, and (2) their progressive replacement by the Mediterranean holm oak (Quercus ilex) forest at the lower altitudinal range of their distribution area in the Montseny mountains. For testing such hypotheses, we studied (a) the changes in distribution of beech forests and heather heathlands since 1945, and (b) the current health and recruitment status of beech stands at their lower altitudinal range. Finally, in this study we discuss the possible relative impact of warming and land management on these changes.

\section{Materials and methods}

\section{Study site and meteorological data}

The study area, the Montseny mountains, declared Natural Park in 1977 and UNESCO's Biosphere Reserve in 1978 (longitude $2^{\circ} 16^{\prime}$ to $2^{\circ} 33^{\prime} \mathrm{E}$, and latitude $41^{\circ} 42^{\prime}$ to $41^{\circ} 52^{\prime} \mathrm{N}$ ), is sited in the Mediterranean region. However, the climate at the highest altitudes (from 1000 to $1700 \mathrm{~m}$ ) is temperate. The average rainfall is ca. $1000 \mathrm{~mm}$, and the mean annual temperature is ca. $7^{\circ} \mathrm{C}$ at the top of these mountains (1706 m a.s.l; Fig. 2).

Meteorological data (temperatures and precipitation) since 1940s were provided by a meteorological station situated at the Turó de l'Home peak at $1706 \mathrm{~m}$ of altitude, and by a meteorological station situated at the base of the mountains, in Cardedeu, at $195 \mathrm{~m}$ of altitude. During the study period, the difference of mean annual temperature between these two stations is $7.7^{\circ} \mathrm{C}\left(\mathrm{SD} 0.4^{\circ} \mathrm{C}\right.$ ) (Fig. 2), i.e., $0.51{ }^{\circ} \mathrm{C}$ every $100 \mathrm{~m}$, which matches expected temperature changes with the adiabatic temperature gradient with altitude.

Past and current distribution of vegetation types: beech forest, Calluna heathland, and holm oak forest.

We used six tools to monitor the changes in the distribution of the vegetation types throughout the last decades:

1. Historical records of vegetation at the three highest peaks (Turó de l'Home, Agudes, and Matagalls of ca. $1700 \mathrm{~m}$ a.s.l) taken since the early 1940 s by several researchers (Llobet, 1947; Bolòs, 1983) and by ourselves in the last four decades. 

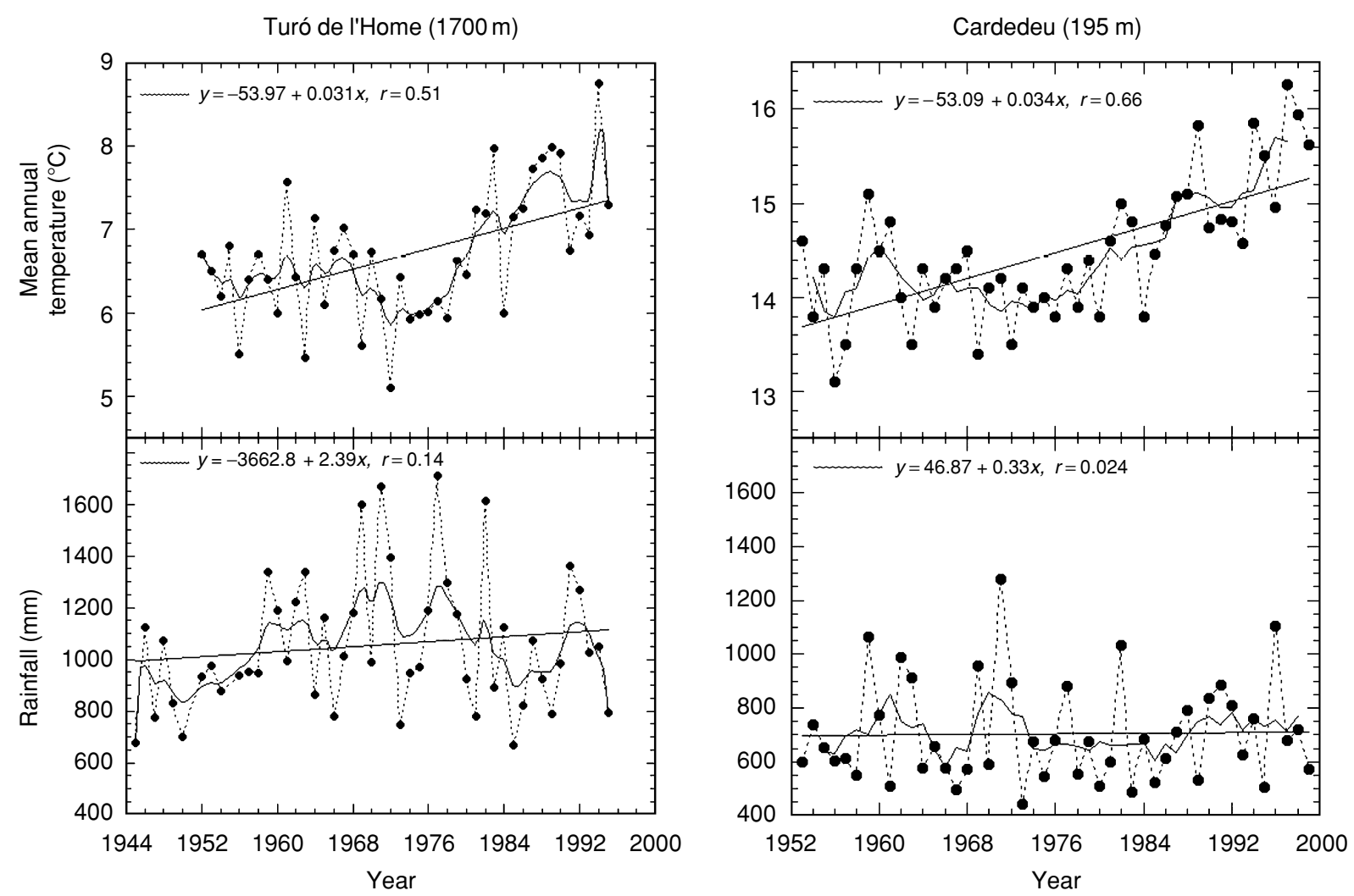

Fig. 2 Climate trends in the studied area (measured in the Turó de l'Home meteorological station at $1700 \mathrm{~m}$, and in the Cardedeu meteorological station, at $195 \mathrm{~m}$ of altitude) during the last five decades. Mean annual temperature and rainfall are also depicted smoothed with five-year running mean. Linear regressions fitted to the annual data are also depicted. Temperature changes were statistically significant at the $P<0.001$ level, whereas rainfall changes were not significant.

2. Photographs of these three main peaks and also from medium altitude sites (Santa Elena, Coll Formic from 800 to $1400 \mathrm{~m}$ a.s.l) taken since the early 1940 s.

3. Orto-rectified aerial photographs from the 1950s to current days (Cartographic Institute of Catalonia).

4. The 'Llobet, 1945 ' Montseny vegetation map (Llobet, 1947) and the Montseny, 1994 forest map of the Department of Agriculture of the Catalan Government.

5. Field visual examination of the Montseny mountains to confirm vegetation patches in 2001.

6. Forestry practices data from local and regional forest administration.

With these tools, we monitored:

a. The upward shift of beech forests at the highest altitudes $(1600-1700 \mathrm{~m})$ replacing heathlands and grasslands.

b. The upward shift of holm oak forests at medium altitudes $(800-1400 \mathrm{~m})$ replacing beech forest and also Calluna and other heathlands, abandoned crop fields, and grasslands. c. The changes in distribution areas of each one of these vegetation types. In order to calculate the area changes we used Adobe Photoshop v. 5.0, Miramon v. 4.0, and Image Tool Software (Wilcox et al., 1996).

\section{Comparison of 'continental' and 'isolated' beech stands at} medium altitudes

In 2001, we monitored three sites of beech forest, with SW aspect, at $850-1050 \mathrm{~m}$ altitude, i.e. at the lowest altitudinal range of beech distribution. In each one of these three sites, four plots of $20 \times 20 \mathrm{~m}^{2}$ inside the 'continental beech stands' (large area of continuous beech stands; see Fig. 5), and $11-13 \mathrm{ca} .400 \mathrm{~m}^{2}$ nearby 'isolated beech stand' plots (small area stands separated from the 'continental' stands and wholly surrounded by holm oak forest; see Fig. 5) were selected. In each one of these 50 plots, we measured the health status of the beech and holm oak trees by following the procedures of the European Union network for forest monitoring (De Vries et al., 1999). Five levels of above-ground damage were established for each species based on visual examination: (0) no damage or less than $10 \%$, (1) $11-25 \%$ slight discoloration or 
defoliation, (2) 26-60\% moderate discoloration or defoliation, (3) more than $60 \%$, severe discoloration or defoliation, and (4) completely decolorated or defoliated tree. We also measured the recruitment of new stems of the two species by counting saplings less than $3 \mathrm{~cm}$ basal trunk diameter coming both from germination or sprouting in each one of the 50 plots.

\section{Statistical analyses}

Regression analyses were conducted between the meteorological data and the years. One-way ANovA analyses were conducted with tree damage or individual recruitment as dependent variables and type of stand (continental vs. isolated) as independent factor. Relative damage data were arc sin transformed to meet normality requirements. All statistical analyses were conducted using STATISTICA v. 5.0 for Windows (StatSoft, Inc., Tulsa, Oklahoma, 1996).

\section{Results}

\section{Warming in the last decades}

During the last 50 years mean annual temperatures have increased ca. $1.2-1.4{ }^{\circ} \mathrm{C}$ both at the top and the base of the mountains (Fig. 2). The main increase occurred in the last 30 years, as it also has occurred on the whole planet (IPCC, 2001b). The linear trend analysis did not reveal a significant change in rainfall during the observation period (Fig. 2). Therefore, the increased temperatures and consequent increased potential evapotranspiration rates have conducted to progressively more arid conditions. However, the sea breezes from the Mediterranean coast keep providing humidity at higher altitudes in summer.

\section{Beech forest upward shift}

On the basis of the above-mentioned historical records, vegetation maps and photographs, we monitored a ca. 70-m upward shift of beech forests at the highest altitudes $(1600-1700 \mathrm{~m})$ in the last 55 years. This upward shift is very easily noticeable since the separation between beech forest and heathlands was very well defined and appeared as a clear horizontal line when observed from far away in the 1950s (Bolòs, 1983). Beech forests have replaced heathlands and grasslands and have reached the summits (Fig. 3), and therefore they have no possibility of further upward shift. In fact, at medium altitude peaks $(1000-1400 \mathrm{~m})$ beech forests become confined (Fig. 4).

\section{Holm oak upward shift: 'continental' vs. 'isolated' beech stands}

On the contrary, at medium altitudes (800-1200 m), and especially on south-facing slopes with higher solar irradiation and temperature, beech is being replaced by holm oak. We have observed that this replacement occurs through a progressive stand 'isolation' process. There is a progressive formation of 'peninsular' and 'isolated' stands of beech trees (Fig. 5). These 'isolated' stands present decreased regeneration and finally are replaced by holm oak forest. This replacement was observed by

Beech upward shift $(70 \mathrm{~m})$ to the top of the mountains

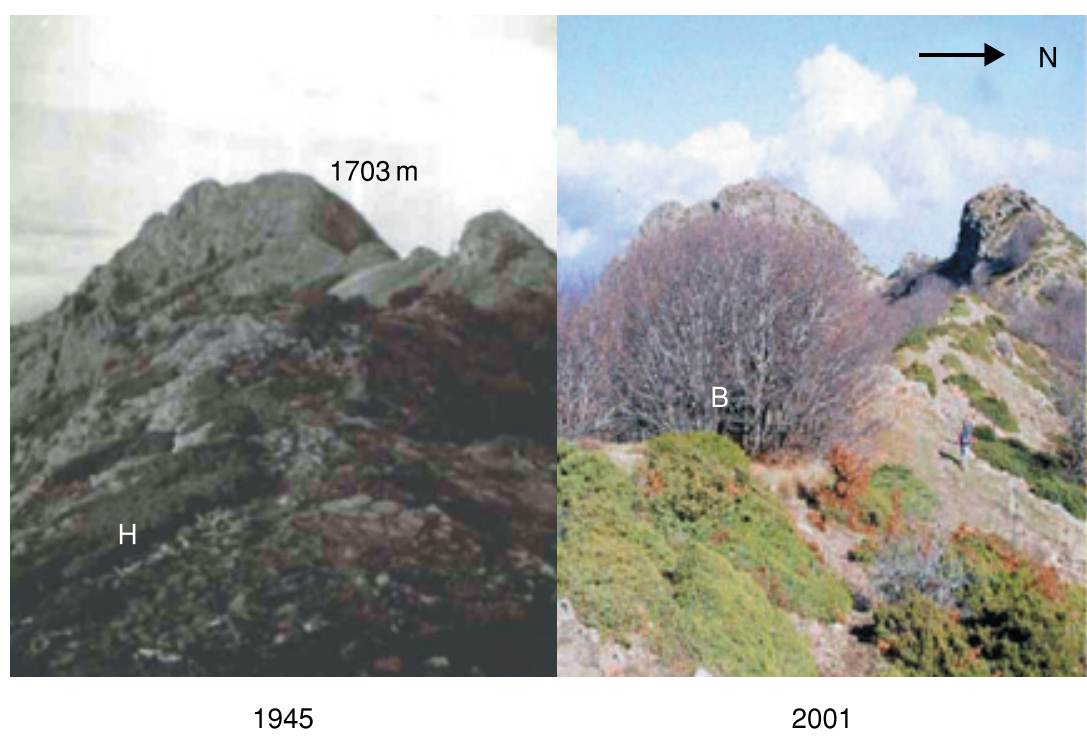

B, Beech; H, Heathland
Fig. 3 Altitudinal upward shift $(70 \mathrm{~m})$ of beech forest to the top $(1700 \mathrm{~m})$ of the highest summits in the Montseny mountains (Catalonia, NE Spain) in the last 55 years. (Les Agudes and Sacarbassa peaks). B: Beech forest (Fagus sylvatica), $\mathrm{H}$ : heathland (Calluna vulgaris and Juniperus nana). 


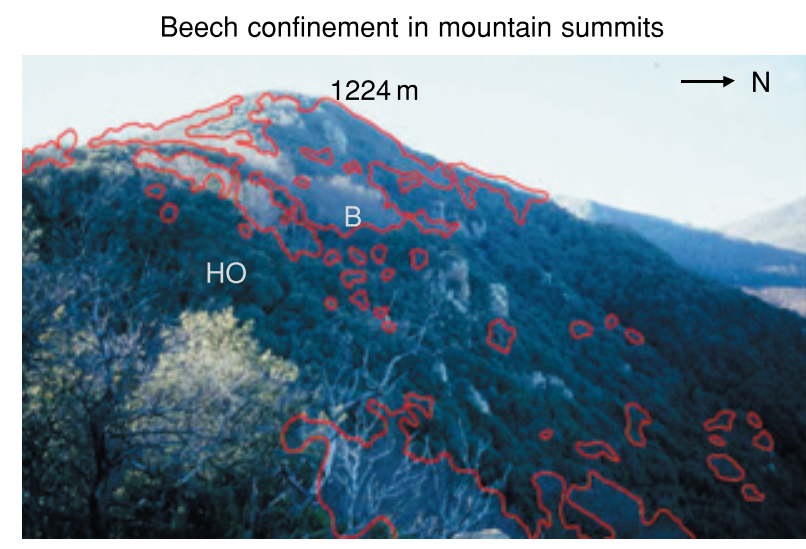

2001

B, Beech; HO, Holm oak

Fig. 4 Example of confinement of beech forest to the top of the medium mountains. (Santa Elena mountain)

Beech progressive replacement by holm oak at medium altitudes $(800-1200 \mathrm{~m})$

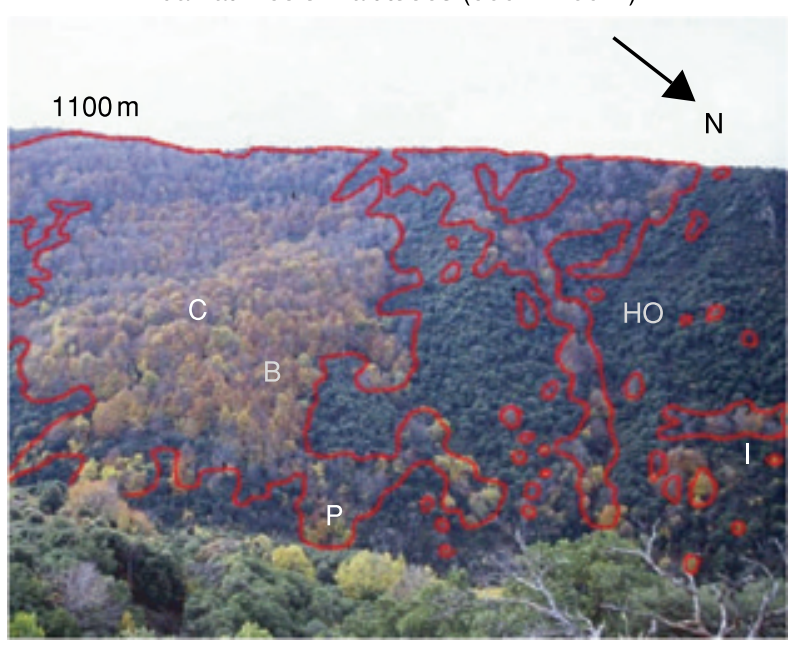

Continental $(C)$, peninsular $(P)$, and isolated (I) beech stands

\section{B, Beech; HO, Holm oak}

Fig. 5 The process of beech forest replacement by holm oak forest at medium altitudes $(850-1050 \mathrm{~m})$ : formation of beech 'continental', 'peninsular' and 'isolated' stands, depending on their size and form. The 'peninsular' and the 'isolated' stands become progressively surrounded by holm oak forest. (Coll Formic-Serra del Navall beech forest)

comparing the Llobet, 1945 Montseny vegetation map (Llobet, 1947) with the Montseny, 1994 forest map of the Department of Agriculture of the Catalan Government (Fig. 6), and by field monitoring of current distribution. Many of these isolated stands on lower south-facing altitudes described in 1945 have now disappeared (Fig. 6).
As a result, according to these maps, beech forest area has decreased by ca. $17 \%$ (650 ha) while holm oak forest has increased its area ca. $20 \%$. Beech forest area decrease is stronger, the lower the altitudinal range of distribution (Fig. 6). At the highest altitudes, above 1300-m, on the contrary, the beech forest area is slightly increasing (Fig. 6). However, 210 ha of the 650 ha decrease in beech forest area were not replaced by holm oak forest but by Castanea sativa, Pinus sylvestris and other tree species due to forest plantations. The other 440 ha decrease in beech forest area were replaced mainly by holm oak forest. Moreover, holm oak forest is not only replacing beech forest but also heathlands, grasslands, and abandoned crop fields (Fig. 7).

Given the possible inaccuracies of these vegetation maps at the small stand scale, and to reinforce the confidence in whether this isolation and replacement process is actually occurring, we compared the health status and the recruitment of new stems in 'continental' and 'isolated' beech stands. We found that beech trees are $30 \%$ more defoliated $(P<0.05)$, there is $41 \%$ less recruitment of beech saplings $(P<0.05)$, and holm oak recruitment is three times higher $(P<0.05)$ in the 'isolated' stands than in the 'continental' stands (Fig. 8).

\section{Holm oak upward shift and Calluna heathland replacement}

At medium altitudes, the Mediterranean holm oak forest is also replacing the Calluna heathland, another temperate vegetation type. Figure 7 shows the changes occurred between 1969 and 2001 in the distribution of vegetation patches on the south-facing slope of one of these mountains (Turó de l'Home) between 1200 and $1700 \mathrm{~m}$ of altitude. In 1969, the Calluna heathland was abundantly distributed and there were almost no holm oaks. In 2001, the Calluna heathland has almost disappeared from the medium altitudes (it only remains at high altitudes, above $1400-\mathrm{m}$ ), and young holm oak forest is invading these medium altitudes, occupying great part of the area and reaching even up to ca. 1400-m of altitude. The Erica heathland keeps a similar area, whereas the fernlands are also retiring to higher altitudes.

\section{Discussion}

\section{Beech upward shift}

Both warming and decrease of anthropic pressure (grazing and its accompanying practices, and forestry) may have favored the upward expansion of beech. The ca. $1.2-1.4{ }^{\circ} \mathrm{C}$ increase in annual temperature seems, however, a strong driver. In Fig. 10 we have drawn a diagram comparing current and 50 years ago altitudinal distribution of vegetation types and temperatures. The increase 
136 J. PEÑUELS \& M. BOADA

MONTSENY MOUNTAINS

Beach forest distribution (1945-1994)
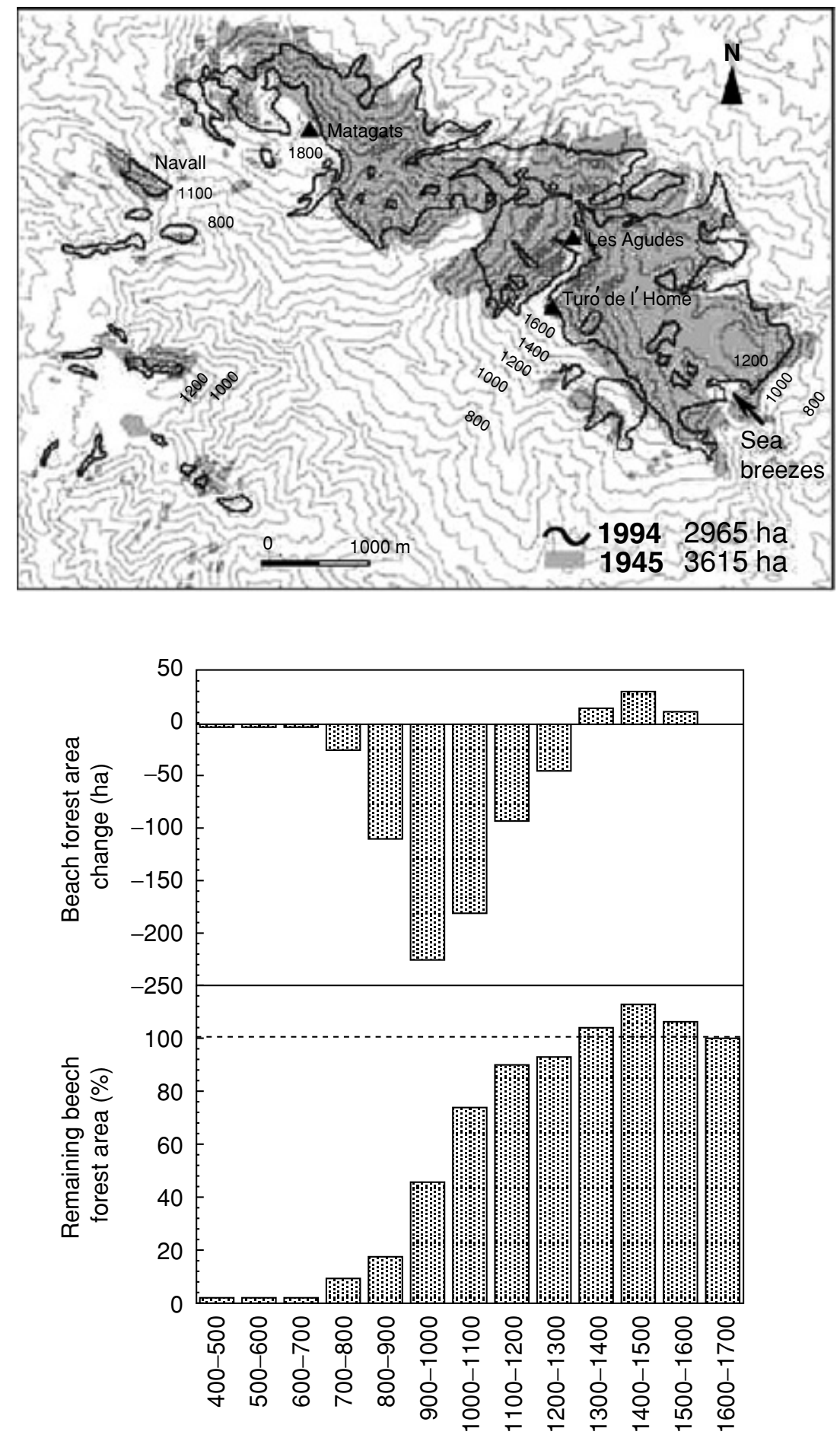

Fig. 6 Comparison of the beech forest distribution in Montseny mountains in 1945 (Llobet, 1947) and 1994 (Montseny, 1994 forest map of the Department of Agriculture of the Catalan Government). Below panels show the changes in beech forest area distributed by altitudes. 


\section{Heathland replacement by holm oak forest at medium altitudes}

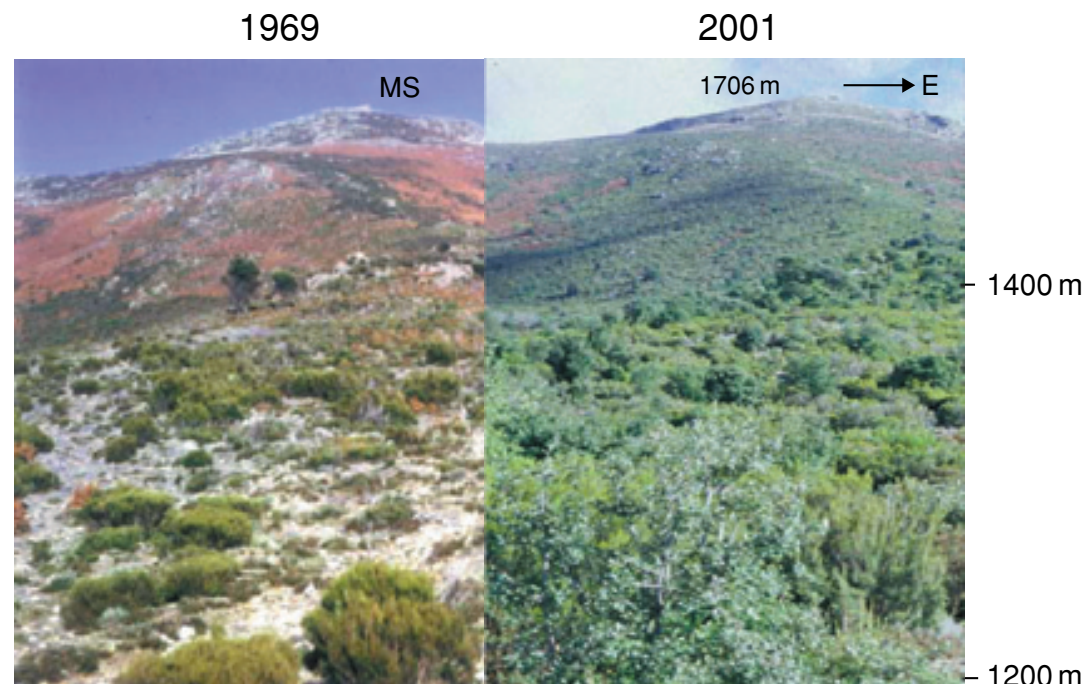

Fig. 7 Pictures showing the replacement of heathlands and grasslands by holm oak forest at medium altitudes (1200-1400 m) in Montseny mountains (Catalonia, NE Spain) from 1969 to 2001. (Turó de l'Home; a meteorological station, MS, is situated on the top of this mountain).

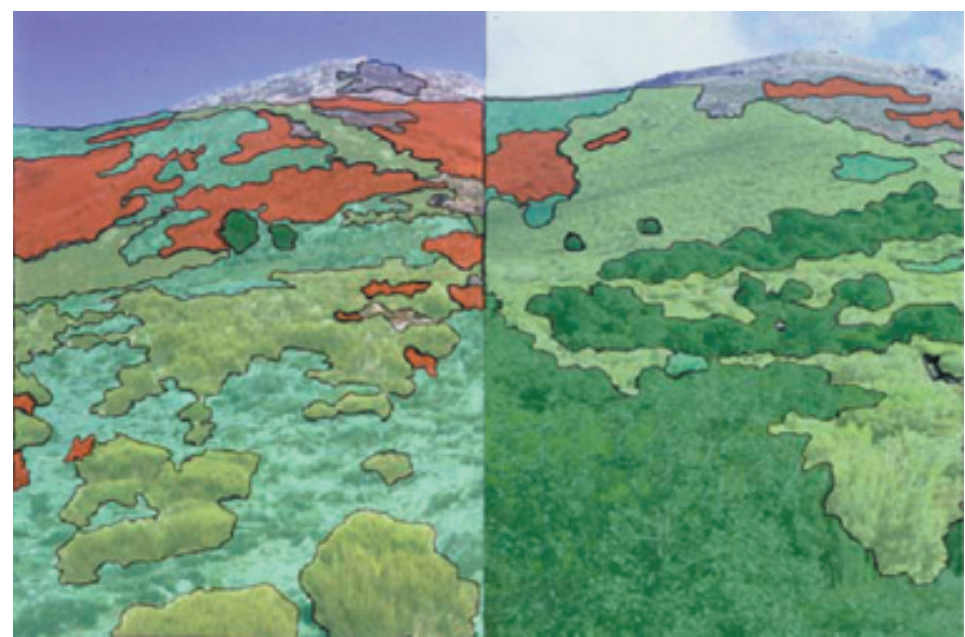

of $1.2-1.4{ }^{\circ} \mathrm{C}$ in the isotherm altitudinal distribution has represented moving temperature conditions about 240-280 m upwards, which is clearly more than the $70 \mathrm{~m}$ beech upwards shift described here. There is an evident limitation for a further upward shift. Beeches have already reached the summit. On the contrary, grazing pressure in those areas has not changed in the last decades. There are now a lower number of herds but similar number of heads, and neither sheep nor goats feed on beech (Bartolomé et al., 1998). However, grazing associated activities such as shrub clearing and burning have decreased, as the area is now a natural park, thus facilitating the beech upward shift in response to climate change. Finally, the cessation of forestry practices does not seem to have influenced much. Forestry practices devoted to favoring beech growth were never applied to these ecotonic upper border of the forests since the individuals, very branchy, were always considered of 


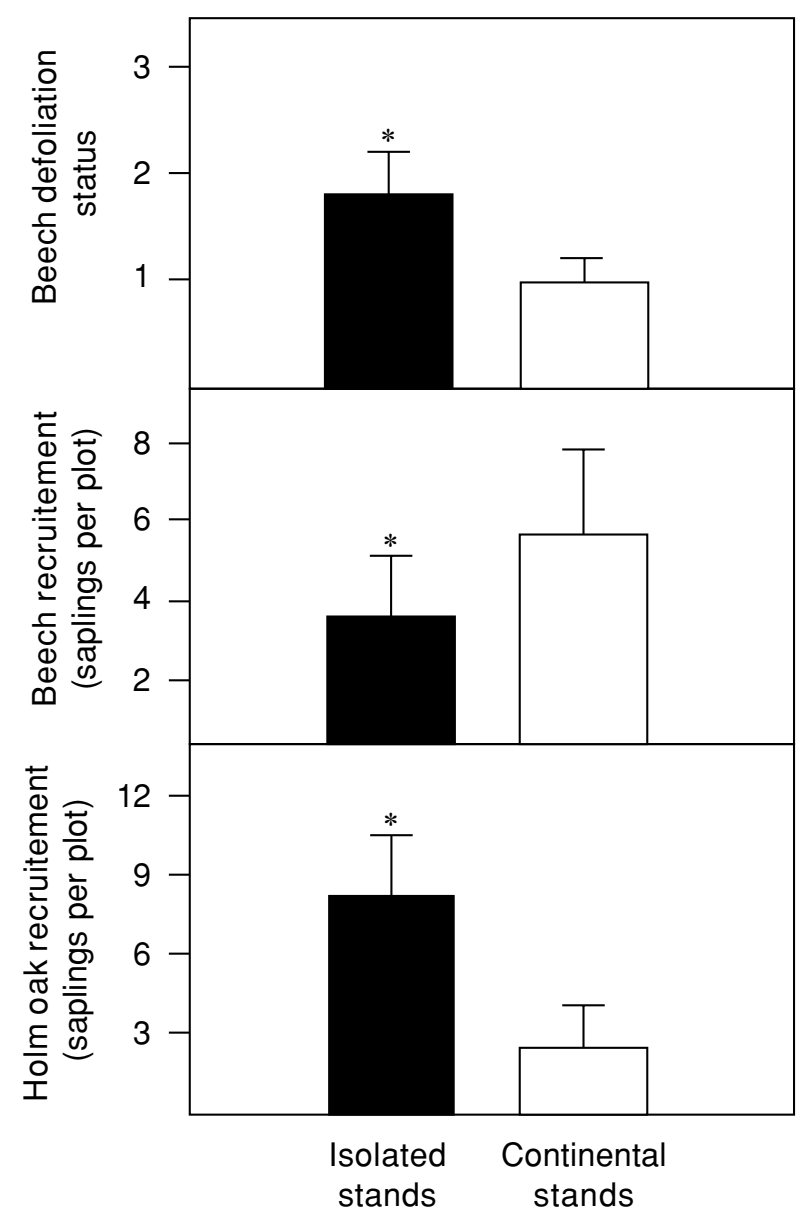

Fig. 8 Comparison of health status (from (0) no damage to (4) $100 \%$ damage; see Materials and methods) and recruitement (number of saplings less than $3 \mathrm{~cm}$ basal trunk diameter per plot, i.e. per ca. $400 \mathrm{~m}^{2}$ ) of beech and holm oak trees in 'continental' and 'isolated' beech stands of SW aspect at 850-1050 m altitude. Error bars indicate SD ( $n=3$ beech forest site means; each one of these means was calculated for 4 'continental' or 11-13 'isolated' $400 \mathrm{~m}^{2}$ stand plots). ${ }^{*} \mathrm{P}<0.05$.

bad quality and of low economical value. Therefore, of these possible-driving factors, the most clear and convincing is the progressive warming with a complementary favoring role of cessation of burning and shrub clearing by shepherds.

\section{Holm oak upward shift and beech forest replacement}

Similar reasoning can be conducted with regards to the beech replacements by holm oak (Fig. 5), an evergreen Mediterranean species better adapted to cope with the currently warmer and drier conditions. Warming seems to play a stronger role than land use changes since forestry practices were (and are) scarce in the lower altitude ecotonic borders of the beech forests, especially in their

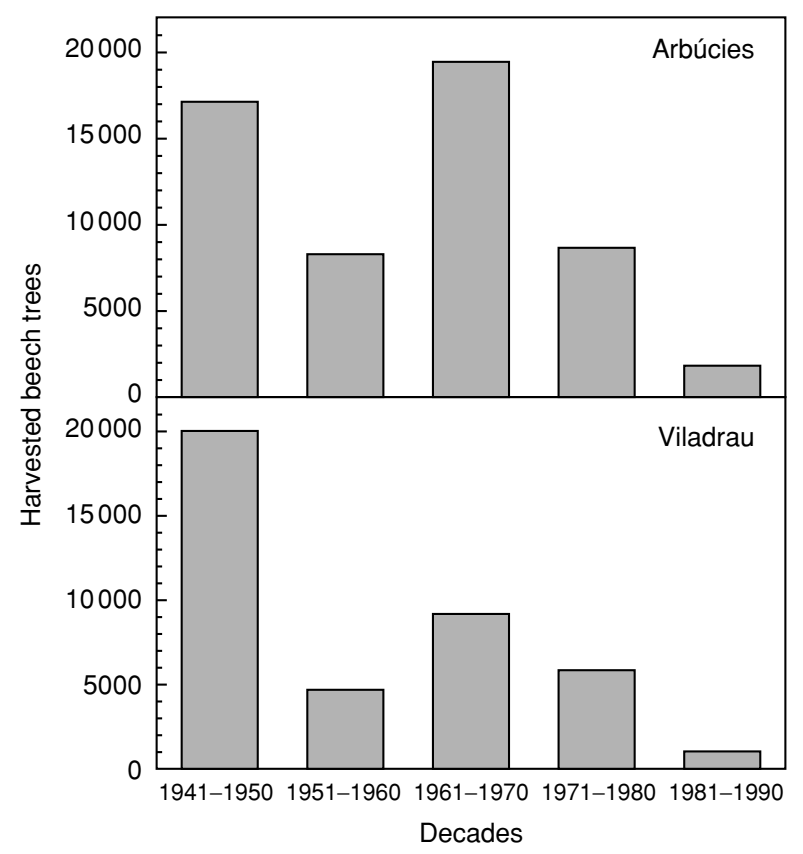

Fig. 9 Number of harvested beech trees throughout the last decades in the Montseny mountains. Data from two of the main municipalities of the park (Arbúcies and Viladrau) for which data is available. The trend is similar in all the municipalities of the park.

isolated stands. The lower beech recruitment in these lower-altitude isolated stands seems linked to lower seed availability and less adequate environmental conditions for germination and seedling survival and development. For example, the likely formation of fogs currently at higher altitudes due to the progressive warming may be involved in these replacements. Fogs have traditionally been accepted as a major factor to explain beech presence in Montseny (Bolòs, 1983). However, they may not be so 'indispensable' as thought since beeches grow well in the western Matagalls area of this Montseny mountains, where there are very scarce fog episodes and where Mediterranean sea breezes are weaker (Fig. 6).

Changes in land-use practices do not seem major drivers. Grazing should favor beech, as sheep and goats feed on holm oak and not on beech (Bartolomé et al., 1998). Forestry practices favoring beech over holm oak for economical reasons have never been important here since these two species had no different economical value, or it was even lower for beech as firewood (Boada, 2001). Moreover, the influence should be even lower in the 'isolated stands' disappearance since these isolated stands, like the above-mentioned upper border trees, have not been much managed given the low economical value of their declining beech individuals. Furthermore, there were neither recent harvesting (the 


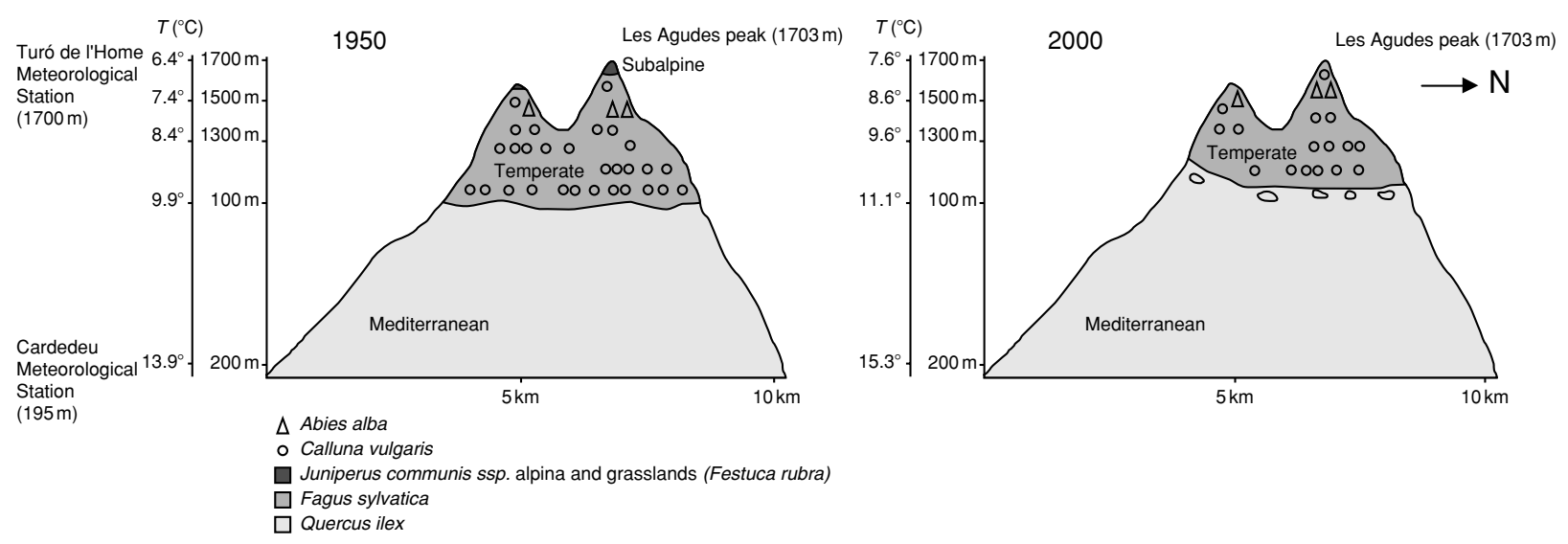

Fig. 10 Sketchy diagram of altitudinal shifts in the distribution of vegetation types and temperatures in the Montseny mountains in 1950 (Llobet, 1947; Bolòs, 1983) and in 2000. The transect goes from south to north, across the Agudes peak.

number of harvested beech trees has decreased throughout the last decades as shown by the data from two of the most important municipalities of the park for which we have more complete data, Fig. 9) or fires (there were no important fires in the beech forests and much less in the last two decades of park administration) that might have accounted for the decrease in the beech distribution area.

\section{Holm oak upward shift and Calluna heathland replacement}

The replacements of Calluna heathland by young holm oak forest (Fig. 7) show a rapid succession that apart from warming has another important driver in land use changes. This holm oak upward shift to such amazing altitudes as $1400 \mathrm{~m}$ is made possible because warming generates adequate conditions at higher altitudes than in earlier decades. However, another important factor in this replacement of vegetation types is the cease of shepherd firing practices. During the decades previous to the 1980s, burning and grazing maintained Calluna heathland and suppressed the growth of shrubs and holm oaks. After the early 1980s, when fire practices were forbidden, and temperatures started to rise, shrubs and holm oak started to gain dominance.

\section{Conclusion and final remarks}

The shifts and replacements described here show that the Mediterranean biome is moving into the cold-temperate boundary as the temperate forests and heathlands withdraw to higher altitudes. The beech upward shift at high altitudes and the beech and heather replacement by holm oak at medium altitudes seem mostly due to warming, but land-use practice changes (cease of shepherd firing) have made it possible. It is likely that the other mountainous areas of the Mediterranean region present similar shifts and replacements in response to climate and land use changes. These changes in vegetation distribution constitute a new indication of complex global change effects on life in mountain ecosystems.

\section{Acknowledgements}

We very much thank the technical help and the comments provided by S. Sanchez, Dr I. Filella, Dr D. Saurí, Dr J.E. Llebot, Dr M. Vilà, Dr F. Rodà, Dr F. Lloret, Dr J. Terradas, Dr J. Bartolomé, J. Duch, M. Meseguer, P. Comes, C. Dalmases, C. Stefanescu, J. Soler, R. Milego, M. Rivera, and R. Ogaya. This research was performed under the auspices of the projects CICYT REN2000-0278 and REN2001-0003 (Spanish Government). We also thank the Diputació de Barcelona for continuous help and funding to study Montseny ecosystems.

\section{References}

Bartolomé J, Franch J, Plaixats J et al. (1998) Diet selection by sheep and goats on Mediterranean heath-woodland range. Journal of Range Management, 51, 383-391.

Boada M (2001) Manifestacions del canvi ambiental global al Montseny. PhD Thesis, Autonomous University of Barcelona, Bellaterra, Spain.

Bolòs O (1983) La vegetació del Montseny. Diputació de, Barcelona Press, Barcelona.

Bolòs O, Vigo J (1990) Flora Dels Països Catalans. Barcino Press, Barcelona.

De Vries W, Reinds GJ, Deelstra HD et al. (1999) Intensive Monitoring of Forest Ecosystems in Europe. Technical Report 1999. EC, UN/ECE 1999, Brussels, Geneva.

Gates DM (1993) Climate Change and its Biological Consequences. Sinauer Associates Inc., Sunderland, Massachusetts.

Grabherr G, Gottfried M, Pauli H (1994) Climate effects on mountain plants. Nature, 369, 448 .

IPCC (2001a) Climate change 2001: impacts, adaptation and vulnerability. In: Contribution of Working Group II to the Third 
Assessment Report of the Intergovernmental Panel on Climate Change (eds McCarthy JJ, Canziani OF, Leary NA et al.). Cambridge University Press, Cambridge.

IPCC (2001b) Climate change 2001: the scientific basis. In: Contribution of Working Group I in the Third Assessment Report of Intergovernmental Panel on Climate Change (eds Houghton JT, Ding Y, Griggs DJ et al.). Cambridge University Press, Cambridge.

Kullman L (2001) Twentieth century climate warming and treelimit rise in the Southern Scandes of Sweden. Ambio, 30, 72-80.

Llobet S (1947) El Medio y la Vida en el Montseny. Estudio Geográfico. Premio Menéndez Y Pelayo, 1945. CSIC Press, Madrid.

Parmesan C, Ryrholm N, Stefanescu C et al. (1999) Poleward shifts in geographical ranges of butterfly species associated with regional warming. Nature, 399, 579-583.
Peñuelas J, Filella I (2001) Phenology: responses to a warming world. Science, 294, 793-795.

Peñuelas J, Filella I, Comas P (2002) Changed plant and animal life cycles from 1952 to 2000 in the Mediterranean region. Global Change Biology, 9, 531-544.

Walther G-R, Post EP, Convey P et al. (2002) Ecological responses to recent climate change. Nature, 416, 389-395.

Wardle P, Coleman MC (1992) Evidence for rising upper limits of four native New Zealand forest trees. New Zealand Journal of Botany, 30, 303-314.

Wilcox D, Dove B, McDavid D et al. (1996) Image Tool for Windows (v. 2.00). The University of Texas Health. Science Center in San Antonio, USA.

Woodward FI (1987) Climate and Plant Distribution. Cambridge University Press, Cambridge. 